\title{
Analysis on Credit Risk Assessment for Accounts Receivable Supply Chain Financing Based on Credit Insurance
}

\author{
Bi Keran ${ }^{1, *}$, Hua Zheng ${ }^{1}$, Shi Qinwen ${ }^{1}$ and Zhu $\mathrm{Yu}^{1}$ \\ ${ }^{1}$ Financial Management, Hohai University, West Focheng Road No.8, Nanjing, Jiangsu province, China
}

\begin{abstract}
This paper studies the model of accounts receivable supply chain financing based on credit insurance from the perspective of banks. First of all, the paper analyzes two different financing modes of the innovative model - the pledge financing mode and the factoring financing mode. Secondly, the paper explains the sources of credit risks for accounts receivable supply chain financing under credit insurance, and the necessity of using credit insurance. The sources of credit risks mainly include: the enterprises' comprehensive strength under systemic and non-systemic risks, status of accounts receivable, supply chain operation, performance of insurance companies, and so on. In addition, based on the credit risks explained in this paper, the risk assessment system and the credit risk assessment model are built. At the end, the paper offers three suggestions for the banks' financing risk control: bank should carefully check the policy's exclusions clauses; bank must carefully check the authenticity of accounts receivable; bank can use dynamic monitoring on qualification checking for financing enterprises, core enterprises and insurance companies.
\end{abstract}

\section{Introduction}

For most enterprises, difficult and expensive financing has always been a major obstacle to development, and they are directly adversely influenced by issues related to capital constraint on supply chain performance and competitiveness. Under such background, the accounts receivable supply chain financing based on credit insurance, as a new option of financing modes in China, has won the attention of commercial banks, enterprises and insurance companies. To make the financing mode accepted by all participants, proper credit risk assessment should be attached with importance and run through its implementation. ${ }^{[1]}$

\section{Accounts receivable supply chain financing}

The accounts receivable supply chain financing mainly refers to the way in which the supply chain enterprises get bank loans by providing it with uncollected accounts receivable as collateral.

\subsection{Analysis of financing modes}

\subsubsection{Pledge financing}

The pledge mode of accounts receivable supply chain financing refers to the way in which the supply chain creditors use their undue accounts receivable claims as collateral to apply for and receive loans from banks and other credit institutes. As a type of collateral, the accounts receivable by itself offers an automatic repayment mechanism to allow the loan to be paid-off with the collection of accounts receivable.

\subsubsection{Factoring financing}

The factoring mode of accounts receivable supply chain financing refers to the way in which the financing enterprises of upstream supply chain transfer their undue accounts receivable to the factoring bank to apply for and receive loans, which is a way of reverse factoring.

\subsection{The sources of credit risk}

The accounts receivable supply chain financing based on credit insurance is essentially a closed ring of financing, and different from traditional financing methods, it has a great advantage in controlling credit risk sources. This paper will divide the major risk sources into systemic and non-systemic ones and carry out its analysis based on which. ${ }^{[2]}$

\subsubsection{The systemic risk}

The systemic risk refers to the situation in which most enterprises of certain industry or the whole market are adversely influenced due to major changes of macroeconomic environment or industry development factors. The status of the supply chain to which the enterprises belong makes the main cause of systemic risk. 
The financing will be adversely affected either by changes in supply chain competition or by the excessive number of uncertain participants who have joined during the financing.

\subsubsection{The non-systemic risk}

\subsubsection{The enterprises' comprehensive strength}

As the main source of repayment for accounts receivable financing, comprehensive strength of the supply chain's core enterprises and financing enterprises greatly influence the credit risk threatening commercial banks. The comprehensive strength of an enterprise consists of the following eight elements: basic quality, solvency, profitability, operation capacity, innovation ability, credit record, growth potential and status of accounts receivable. Those elements reflect the enterprise's operational and credit status.

\subsubsection{Status of accounts receivable}

As the value of trading assets needs to be assessed, the status of accounts receivable should be deemed the top priority in the bank's inspection job. Besides, it is also very important to check whether the accounts receivable were generated by the core and financing enterprises during their day-to-day operations inside the financing ring. The financing will be disrupted if it is conducted with accounts receivable that are generated between the financing enterprise and the debt enterprises outside the financing ring as supporting credit assets.

\subsubsection{The risk from supply chain operation}

The foundation for accounts receivable supply chain financing is that the credit of all supply chain enterprises is taken as a whole. When a company of the supply chain performs poorly, other companies will be consequently adversely impacted. Such impact can spread to the whole supply chain and lead to difficult recovery of loans to the bank.

\subsubsection{The performance of insurance companies}

To avoid default of the core enterprise, the financing enterprise turn to the insurance company for solutions. In this case, the insurance company's good performance can provide reliable credit assurance to the accounts receivable. Because, if the core enterprise defaults, the insurance company will pay and recover the compensation. Therefore, should the insurance company be suffering from poor performance, it may fail to pay compensation, which may lead to financing failure to the insured enterprises and the whole supply chain's breakage. ${ }^{[3]}$

\section{The necessity of credit insurance in accounts receivable supply chain financing}

The credit insurance applied in accounts receivable supply chain financing refers to the operation in which the insurance is covered by the financing enterprise, taking the core enterprise's credit as the subject matter. When the core enterprise defaults due to force majeure, the due and unpaid amount of money will be settled by the insurance company, and limited payment of reparation will also be made to the bank.

\subsection{The core enterprise's credit capacity may be insufficient}

When the core enterprise's credit capacity is insufficient, it may not be able to facilitate the financing enterprise's loan application depending on its own line of credit. In such a case, the financing enterprise can only use additional credit enhancement. With credit insurance, the loans can be released by the bank depending on regular methods of supply chain finance operation procedures, and when default happens, the credit risk can be resolved through the insurance company's credit assurance. ${ }^{[4]}$

\subsection{Credit insurance can effectively reduce the financing enterprise's financing cost}

Generally speaking, the premium rate of credit insurance is not more than $2.5 \%$ of the loan's total amount. With credit insurance, the financing enterprise's creditworthiness can be assessed by the insurance company using professional mature methods of investigation, which can rectify the information asymmetry between commercial banks and enterprises. When the insurance company's investigation is done and the credit insurance is covered, the financing enterprise can use the insurance to enhance its credit in financing, so as to reduce the loan's interest rates.

\subsection{Reduce risk causing factors threatening the banks}

On the one hand, the participation of credit insurance and the insurance company can effectively rectify the information asymmetry between commercial banks and enterprises, thus reducing the credit risk caused by which. On the other hand, when the premium is collected from the insured enterprise, the insurance company becomes responsible for the payment of principal and interest. Therefore, it must play a role in the investigation and subsequent use of the loan. This can create a risk sharer for the bank and ensure the loan's repayment. ${ }^{[5]}$ 


\section{Construction of the credit risk assessment model for accounts receivable supply chain financing based on credit insurance}

\subsection{To build a risk assessment index system}

To reduce the influence of subjective factors, structured methods are adopted by this paper in building the credit risk assessment model for accounts receivable supply chain financing based on credit insurance. And taking the credit risk source analysis on which as the foundation, as well as referring to previous studies, the index system as shown in the following table 1 . is built. ${ }^{[6]}$

Table 1 Credit risk assessment index system for accounts receivable supply chain financing based on credit insurance

\begin{tabular}{|c|c|c|}
\hline Target layer & First-level indicator & Second-level indicator \\
\hline \multirow{33}{*}{$\begin{array}{l}\text { Credit risk assessment for } \\
\text { accounts receivable supply } \\
\text { chain financing based on } \\
\text { credit insurance A }\end{array}$} & \multirow{6}{*}{$\begin{array}{l}\text { Risk related to business } \\
\text { environment B1 }\end{array}$} & Risk related to macro-economy $\mathrm{C} 1$ \\
\hline & & Risk related to business circle $\mathrm{C} 2$ \\
\hline & & $\begin{array}{l}\text { Risk related to industry competitive } \\
\text { intensity } \mathrm{C} 3\end{array}$ \\
\hline & & Risk related to industry growth potential $\mathrm{C} 4$ \\
\hline & & Position in industry C5 \\
\hline & & Risk related to commodity price C6 \\
\hline & \multirow{5}{*}{$\begin{array}{l}\text { Risk related to supply chain } \\
\text { relationship B2 }\end{array}$} & Strength of relationship contract C7 \\
\hline & & Previous performance $\mathrm{C} 8$ \\
\hline & & Quality of information sharing C9 \\
\hline & & Product substitutability $\mathrm{C} 10$ \\
\hline & & Cooperation degree C11 \\
\hline & \multirow{7}{*}{$\begin{array}{l}\text { Risk related to the financing } \\
\text { enterprise B3 }\end{array}$} & Operation capability $\mathrm{C} 12$ \\
\hline & & Risk related to product strength $\mathrm{C} 13$ \\
\hline & & $\begin{array}{l}\text { Risk related to leadership and staff quality } \\
\qquad \mathrm{C} 14\end{array}$ \\
\hline & & Risk related to technical level C15 \\
\hline & & Accounts recovery ability C16 \\
\hline & & Loan performance $\mathrm{C} 17$ \\
\hline & & Asset-liability ratio $\mathrm{C} 18$ \\
\hline & \multirow{4}{*}{$\begin{array}{l}\text { Risk related to the core } \\
\text { enterprise } \mathrm{B} 4\end{array}$} & Enterprise scale B19 \\
\hline & & Asset-liability ratio B20 \\
\hline & & Credit-rating B21 \\
\hline & & Profitability B22 \\
\hline & \multirow{5}{*}{$\begin{array}{l}\text { Risk related to status of } \\
\text { accounts receivable B5 }\end{array}$} & Clarity of claims B23 \\
\hline & & Negotiability B24 \\
\hline & & Aging and payment days B25 \\
\hline & & Sales returns B26 \\
\hline & & Turnover of accounts receivable B27 \\
\hline & \multirow{6}{*}{$\begin{array}{l}\text { Risk related to the insurance } \\
\text { company B6 }\end{array}$} & Size and strength B28 \\
\hline & & Risk related to policy terms B28 \\
\hline & & Loss ratio B29 \\
\hline & & Policy pledge rate $\mathrm{B} 30$ \\
\hline & & Policy pledge rate B31 \\
\hline & & bility of recovery in later periods B32 \\
\hline
\end{tabular}

\subsection{The comparison of relative importance between different factors}

To compare pairwise two factors of the same layer using the one of the prior level as criteria, so as to determine its relative importance and establish the fuzzy comparison matrix.

Table 2 Fuzzy comparison matrix

\begin{tabular}{|c|c|}
\hline Scale & Definition and explanation \\
\hline 1 & The two factors are equally important \\
\hline 3 & One factor is slightly more important than the other \\
\hline 5 & One factor is obviously more important than the other \\
\hline 7 & One factor is significantly more important than the other \\
\hline 9 & One factor is overwhelmingly more important than the other \\
\hline $2,4,6,8$ & The middle value of adjacent scales \\
\hline
\end{tabular}

Notes: if the ratio of importance of factor $i$ to factor $j$ is $a_{i j}$, then the ratio of importance of factor $j$ to factor $i$ is $a_{j i}=1 / a_{i j}{ }^{[7]}$ 
Table 3 Form of comparison matrix

\begin{tabular}{ccccc}
\hline $\mathbf{P}$ & $\mathbf{U}_{1}$ & $\mathbf{U}_{2}$ & $\cdots$ & $\mathbf{U}_{i}$ \\
\hline $\mathrm{U}_{1}$ & $\mathrm{a}_{11}$ & $\mathrm{a}_{12}$ & $\cdots$ & $\mathrm{a}_{1 i}$ \\
$\mathrm{U}_{2}$ & $\mathrm{a}_{21}$ & $\mathrm{a}_{22}$ & $\ldots$ & $\mathrm{a}_{2 i}$ \\
$\ldots$ & $\cdots$ & $\ldots$ & $\cdots$ & $\cdots$ \\
$\mathrm{U}_{j}$ & $\mathrm{~A}_{j 1}$ & $\mathrm{~A}_{j 2}$ & $\cdots$ & $\mathrm{A}_{j i}$ \\
\hline
\end{tabular}

$$
\frac{1}{n} \sum_{i=1}^{n} \frac{\sum_{j=1}^{n} a_{i j} W_{j}}{W_{i}}
$$

Use the formula to get the approximate value of the maximum characteristic root $\lambda_{\max }$

\subsection{The consistency checks}

With its principle, the comparison matrix can reduce the influence of unwanted factors to a certain extent.
However, a consistency check is still necessary, because when all comparison results are reviewed, inconsistency may occur.

$$
C I=\left(\lambda_{\max }-n\right) /(n-1) \text {, where } n \text { is the order of }
$$
the comparison matrix.

$\mathrm{CR}=\mathrm{CI} / \mathrm{CR}$

To find out whether the comparison matrix of different orders could pass the consistency checks, the matrix's random index (RI) needs to be introduced.

Table 4 Random Index (RI)

\begin{tabular}{|c|c|c|c|c|c|c|c|c|c|c|}
\hline $\begin{array}{c}\text { The orders of } \\
\text { comparison } \\
\text { matrix } \boldsymbol{n}\end{array}$ & 1 & 2 & 3 & 4 & 5 & 6 & 7 & 8 & 9 & 10 \\
\hline RI & 0 & 0 & 0.58 & 0.89 & 1.12 & 1.24 & 1.32 & 1.41 & 1.45 & 1.49 \\
\hline
\end{tabular}

participation of insurance companies who settle the

When $\mathrm{CR}<0.1$, the comparison matrix shows satisfactory consistency. Otherwise, the comparison matrix needs to be adjusted and revised, so that it can meet the foregoing conditions.

To calculate the weights of the first and the second level indicators using the above method, and finally to gain the weighting by ranking of all indicators to the target. The total weighting by ranking needs to be generated by synthesizing the weights under single criteria from the top down, and finally to gain an index system weight set and the ranking of importance for its elements. When the weighting by ranking is done, it is used to find out which risks should be defined as the banks' major concerns. ${ }^{[8]}$

\section{Suggestions of credit risk control of accounts receivable supply chain financing based on credit insurance}

The risk assessment is the basis of risk control for the bank to deal with applications of financing with credit insurance. Therefore, this paper proposes the following suggestions to credit risk control in accounts receivable supply chain financing based on credit insurance:

\subsection{Closely check the policy's exclusion clauses}

Different from the traditional modes of supply chain financing, the one based on credit insurance includes the claims only when certain conditions are met. Therefore, the policy's exclusion and disclaimer clause should be checked very closely by the bank. Here the suggestion is that the bank may work with the financing enterprise to add conditions that are beneficial to itself as endorsement to the insurance contract before it is signed.

\subsection{Closely check the authenticity of accounts receivable}

When dealing with applications of accounts receivable supply chain financing based on credit insurance, the bank should require that the accounts receivable used in the application must be attached with verification documents issued by the core enterprise and they must be held by the financing enterprise. In this case, the financing enterprise is the creditor, and the core enterprise is the debtor. During pre-financing investigation, the bank should take full advantage of the insurance company's role of underwriter to check the authenticity of accounts receivable used in application. ${ }^{[9]}$

\subsection{Dynamically monitor the qualifications of financing enterprises, core enterprises and insurance companies}

The bank should be aware that the credit qualifications of major participants significantly affect the loan recovery. More participants, more risks. When the insurance company joins the operation, it becomes one of the three risk components, as the other two are the financing 
enterprise and the core enterprise. Therefore, it is important to use dynamic monitoring on all participants, so as to make timely countermeasures and reduce the risk as much as possible.

\section{Conclusion}

The accounts receivable supply chain financing based on credit insurance is a brand-new financial product developed by commercial banks in recent years. Under the background in which development of the supply chain is blocked by fund shortage, and accounts receivable of all industries are increased both in number and payment days, the product is able to utilize the supply chain enterprises' symbiotic relationship, the core enterprises' good credit qualifications and the assurance provided by the insurance companies, to help enterprises in fund shortage overcome their difficulties.

There are different modes of supply chain financing, and the paper studied only one of them - the accounts receivable financing. However, in real use, if characteristics of accounts receivable used in the paper's assessment methods are replaced with the ones of different credit assets, the methods can be applied to more finance modes. Therefore, this paper can be referred to when managing credit risk assessment of different supply chain finances.

\section{References}

1. Daimei, Shi. 2020. Research on accounts receivable pledge supply chain finance of Chinese commercial banks [J]. Huabei Finance.

2. Wenzhong, Li. 2014. The role of guarantee insurance in facilitating small and micro enterprises on financing - the game among banks, enterprises and insurance companies [J]. Insurance Studies (02): 74-84.

3. Shan, Wang. Research on supply chain finance base on credit insurance for small and medium-sized enterprises [D]. Beijing Jiaotong University.

4. Xiong, xiong; Jia, Ma; Wenjie, Zhao; et al. 2009. Credit risk assessment for supply chain finance [J]. Nankai Business Review 012(004): 92-98, 106.

5. Qianqian, Lei; Xin, Su; 2011. Xinzhong, Niu. Preliminary research on the role of commercial insurance in facilitating the small and medium-sized enterprises in financing [J]. Financial Theory \& Practice (05): 49-52.

6. Longze, Song. Research on credit risk assessment for accounts receivable supply chain financing [D]. Guizhou University of Finance \& Economics.

7. Rui, Yan; Fengping, Yan. 2019. Risk assessment for scientific and technological enterprises of small and medium sizes based on fuzzy comprehensive evaluation method [J]. Journal of Heilongjiang Bayi Agricultural University v.31; No.153(04): 93-99.

8. Binbin, Bao; Jungang Shao. 2014. Risk assessment of supply chain finance for small and medium-sized enterprises based on AHP [J]. Enterprise Economy (05): 90-94.

9. Jia Ma. 2008. Financing mode analysis and risk control on supply chain finance [D]. Tianjin University. 